
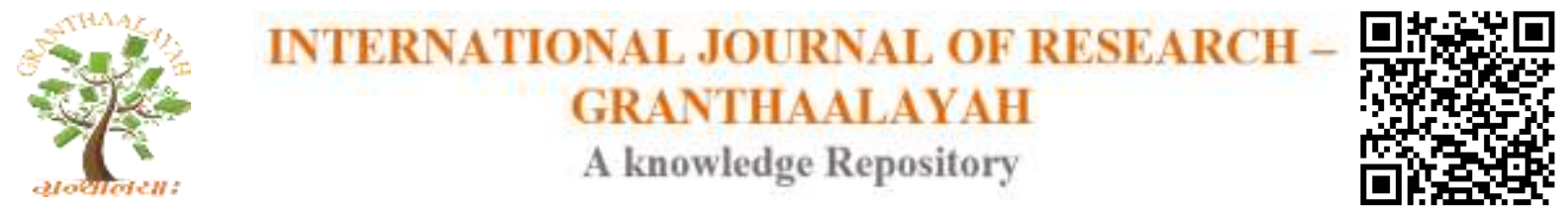

Social

\title{
EFFECT OF MATHEMATICS LEARNING ON THE DEVELOPMENT OF MATHEMATICS CREATIVITY
}

\author{
Dr. Jyoti Sharma *1 \\ *1 Associate Professor, Cluster Innovation Centre, University of Delhi, India
}

\begin{abstract}
The paper presents an empirical study done in Indian classrooms to understand the effect of mathematics learning experiences on the development of mathematics creativity. The study was designed in two stages, at stage I, it was planned to find out scope, practice and promotion of creative thinking in mathematics classroom; teachers' own engagements with creative mathematical task and teachers' attitude towards mathematics creativity. Stage II was designed to find out responses of students and teachers in mathematics creativity task. Responses of students were analyzed on the basis of three criteria: Originality, Mathematical Descriptors and Approach. The analysis of the study highlighted the conditioning of minds while learning, teaching and doing mathematics. It brings to our attention the more serious issues about how mathematics is presented and taught to the students.
\end{abstract}

Keywords: Mathematics Creativity.

Cite This Article: Dr. Jyoti Sharma. (2017). "EFFECT OF MATHEMATICS LEARNING ON THE DEVELOPMENT OF MATHEMATICS CREATIVITY." International Journal of Research - Granthaalayah, 5(7), 151-158. 10.29121/granthaalayah.v5.i7.2017.2117.

\section{Introduction}

Creativity is an important but a complex idea to define. Though there is huge diversity the way creativity is defined, exemplified and measured, yet there is an agreement of opinion that creativity is a significant construct of human cognition. J.P. Guilford (1949) was among the founder researchers who viewed creativity distinctively from intelligence and emphasized the role of creativity in human development. According to Guilford (1950):

- Creativity is a natural resource

- Creativity can be studied objectively

- Any effort to encourage creativity would pay high dividends to society (as cited by Runco 2014)

To begin with these foundations, creativity has been discussed in different perspectives, ranging from creativity as an entity or a descriptor; creativity as a product or a process; creativity as an inherent trait or an acquired trait and from biological correlates of creativity to the developmental 
correlates of creativity. None of these are stand-alone perspectives. As summarized by Runco (2014) 'Creativity is closely related but distinct from intelligence, imagination, insight, divergent thinking and other similar cognitive behaviors'.

An idea is considered creative if it is original, surprising and non-routine. Creative ideas must be functional and expressive. For example, solution of a problem is considered creative if it is new and also provides solution to the problem. It can be considered more creative if the solution is simpler than the other previous solutions or it has wider application or it gives all together new perspective of the problem.

Simonton (2014) highlighted three major perspectives to discuss creativity:

- Process that generates a creative idea

- Person who thinks and delivers a creative idea

- Product which represent or communicate creative idea

Amabile (1996), Stein (1953) Sternberg \& Lubart (1995) all agreed to a common definition of creativity: as an ability to produce work that is:

- relatively novel

- high in quality

- appropriate to the task at hand ( as cited by Zhang \& Sternberg 2014)

Adding cultural dimension, Flaherty (2005) defined, 'an idea is creative if it is both novel and useful in a particular social setting'. Andersen (2005) further added that creativity must lead to a product that is original and possess utility.

There is also an understanding that creativity plays a significant role in everyday activities and in advanced cognitive activities such as invention, innovation and expansion of knowledge.

Development theories of human development (Piaget 1970, 1976; Kohlberg 1981) have greatly influenced the educational perspective of creativity and supported the claim that creative potentials of individuals can be fostered and enhanced by creating opportunities and by providing suitable learning environment. On the contrary, there are research evidences that teachers prefer students who are courteous and easy to fall in line. Teachers don't prefer students who are non-conventional in their thinking. It has also been found that teachers have stereotyped approach towards creativity (Raina 1975, Torrance 1963a; as cited by Runco 2014). Lee and Seo (2006) found that teachers define creativity in terms of actual product and productivity but they ignore or underestimate students who have high creative potential but they lack skills necessary to complete a finished product. Creativity as an approach has an important role to play in educational practices, particularly, in school mathematics education. Fostering creative thinking can be used as a pedagogical tool to develop positive attitude towards mathematics.

For most of the students and teachers, mathematics is a discipline that is highly structured, precisely defined, strictly organized and gives little freedom to experiment with ideas. Mathematicians take pride in working with highly sophisticated and precise system of symbols, notations and representations. Any new mathematical idea has to pass through the test of precision, generalization and formalization before entering in the domain of mathematics. 
The frequently used methods of introducing a mathematical concept consist of well formulated definitions, mostly using abstract symbols, various terms and conditions under which the concept is defined. All three essential ingredients, namely, definitions, symbols and conditions are presented to learners as sacrosanct. Learners are trained to use mechanical procedures in a religious manner, practiced in step by step procedure with little or no flexibility of exploration.

There is another perspective of viewing mathematics where mathematics is a field of ideas, insight, innovation and freedom. It possesses all attributes of a creative field. It empowers learners to think beyond limits - till infinity. Mathematics is a discipline which originated to the needs of society; it has spread across civilizations, communities and cultures as a social and cultural force; it has developed and still developing because of the shear passion and creativity of those remarkably genius mathematicians who are in love with its simplicity, elegance and maturity.

Mathematics has novelty of ideas; synergy of thought process; courage of validation \& generalization; power of abstraction, scope of application and freedom of expansion. All mathematical concepts are abstract yet it has systematized the entire universe using equations and identities. It is disheartening to see that the creative perspective of mathematics as a subject of study is either ignored or kept out of reach from young learners. Students are given no opportunity to play with mathematical ideas; to communicate mathematically or to work mathematically from different perspectives. Mathematics teaching shall be the best way to promote creativity among learners and eliminating fear and disliking for mathematics among learner.

As creativity fosters in a stimulating and encouraging learning environment (Runco 1991b), teachers shall create positive conditions of learning and initiate discussion that promote alternate thinking in mathematics. What if teachers do not provide opportunities for creative mathematics dialogue in the class, instead use different kinds of squelchers to snub creative thinking? Davis (1999) submitted that like habit, use of such squelchers tend not to promote creativity.

With this understanding, the present research aimed to see the effect of mathematics learning on the development of mathematics creativity. The research as an empirical work was planned in regular Indian classroom setting where mathematics classroom discourses become more and more unilateral as student progresses from primary to higher grades. Scope of investigation, multiplicity of different perspectives, mathematization of everyday experiences, informal mathematical communication and use of mathematics vocabulary in everyday communication gradually start shirking as student progresses from elementary years to higher grades of mathematics learning. The excitement of opening the problem instead the pressure of solving it; intensity of discussing the possible approaches to solve the problem instead of following a fixed route to solve the problem; sense of choosing the most elegant way of solving the problem instead of practicing the only right way of solving a problem are essential strategies to promote creative approach towards mathematics learning. The present research tried to see how mathematics learning discourses that take place in regular Indian classroom effect development of creative thinking in mathematics.

The research aimed to answer following research question: 
How does the nature of mathematics learning/teaching discourses effect creative thinking in mathematics?

\section{Methodology}

The paper presents an empirical study done in Indian classrooms to understand the effect of mathematics learning experiences on the development of mathematics creativity. For the research purpose, Mathematics learning experience is defined as all kind of learning experiences of mathematics learners. These learning experiences can be everyday mathematics discussions and practices that take place during classroom teaching learning process. It also includes learning imbibed through a mathematics course taken as a student or a teacher.

Mathematics creativity is defined as thinking creatively in a mathematical situation that can be demonstrated by observable behaviors such as a response, a question, an expression or an action. It also includes problem solving behavior that promotes to see a link between unfamiliar nonmathematical situations and already learned mathematical experiences.

\section{Objectives}

The study was designed in two stages, at stage I, it was planned to find out scope, practice and promotion of creative thinking in mathematics classroom; teachers' own engagements with creative mathematical task and teachers' attitude towards mathematics creativity. Stage II was designed to find out responses of students and teachers in mathematics creativity task. Following objectives were planned for stage I and stage II:

\section{Objectives for Stage I:}

1) To find out nature of classroom discourses during mathematics teaching, both at school level and college level

2) To find out attitude of college mathematics teachers about mathematics creativity

\section{Objective for Stage II:}

1) To find out level of creative thinking among

- School students at early middle grade

- University students with mathematics major

- College mathematics teachers

2) To find out relation between nature of mathematics discourses and response to mathematics creativity task

Sample: Study was limited on a selective sample selected through purposive random sampling. Sample consisted of three different groups as per the table I given below:

Table 1: Distribution of sample

\begin{tabular}{|l|l|l|}
\hline Group A & $\begin{array}{l}\text { University mathematics teachers teaching mathematics to undergraduate } \\
\text { students }\end{array}$ & 20 \\
\hline Group B & University students who have completed bachelor degree in mathematics & 20 \\
\hline Group C & School students studying in grade VI & 20 \\
\hline
\end{tabular}




\section{Methodology for Data Collection}

For stage I, forty hour mathematics classroom observations were made to find out the nature of classroom discourses that could promote mathematics creativity. Ten hour observations were done at each level, middle grades (grade VI-VIII); secondary grades (IX and X); senior secondary grades (grade XI-XII) and Mathematics (major) classes at college level. Due permissions were taken from the concerned authorities. For the present study, classroom discourses, such as various methods adopted by teachers to promote mathematics creativity by asking questions, allowing students to raise questions, fostering culture of open discussion, encouraging alternate problem solving strategies, linking mathematics with everyday experiences, creating opportunities for out of box thinking and stimulating informal but challenging mathematical discussions in the class were observed and a detailed account was prepared which was used for data analysis.

For stage II, three different tasks were developed for three different sample groups.. Tasks were developed keeping in mind the mathematics learning experience of each group. Mathematics learning experience was calculated on the basis of number of years the individual had studied or taught mathematics.. Students of grade VI had five years of formal mathematics learning experience whereas sample of Group B had fifteen years of mathematics learning experience including core mathematics and higher mathematics. Similarly, college teachers were subject experts with minimum qualification of master's degree in mathematics and minimum one year teaching experience of teaching undergraduate students. Tasks designed for each group were simple with ample scope of creativity. It was also kept in mind to consider age appropriate concepts in designing the task.

Task A for Group A: Instructions: Describe each picture mathematically.

It consisted of a set of randomly chosen five pictures taken from open source using Google search engine.

Task B for Group B: Instructions: Make your own numeral system.

Participants were asked to make their own numeration system. Based on their understanding of international numeration system, they could use different symbols, they could change the base or they could alter the rules to change the working of numeration system.

Task C for Group C: Instructions: Write dialogues between two numbers.

Participants who were school students were asked to write at least two dialogues between any two numbers of their choice.

Each response was assessed on the basis of following three criteria:

i. Originality: newness, surprising, non-routine

ii. Mathematics descriptors: flexibility of using mathematical concepts and vocabulary, frequency of concepts, variety of concepts, complexity of concepts

iii. Approach: holistic, purposive, logistic 


\section{Task Administration and Data Analysis}

Appropriate instructions were given to each group before administering the task. Task was administered in a lively environment. Participants were encouraged to give their responses with an open mind, flexibly and as creatively as possible. Data so collected was analyzed qualitatively.

\section{Data Analysis of Stage I}

Observations done in mathematics classrooms highlighted serious issues. As discussed earlier, observations were made regarding those classroom opportunities created by teacher that fostered and guided creative thinking among students. Observations were also focused on those crucial moments of possible creative thinking that were missed during classroom discourse. Efforts were made to observe learning environment of the class which was directly related to teacher's attitude towards teaching.

Forty hour observations that were spread across different levels gave valuable insight about opportunities available to students for thinking creativity in mathematics classroom. There were instances of mathematics humor, unusual ideas and experimentation with different methods (though these were not mathematically correct most of the time) in middle grade classes. It was also the most energetic and lively age group among all four. Teachers were open to new ideas; sometimes they would pat the child with an encouraging remark or they would make an alternate statement in response to the child's response just to promote for more advanced thinking or they would open the child's comment for other students' observations and responses and sometimes, they would add some value points. Creative thinking opportunities in senior classes (secondary to college level) were highly stereotyped. In most classes, teachers were the information given and students were following instructions. Discussion between teacher and students was limited only to the immediate task they were engaged in. Lessons were taught in a highly rigid manner with no scope of alternate thinking, giving an impression that whatever was taught by the teacher is sacrosanct. In a thirty minute teaching duration, average time of any kind of discussion in the class was less than ten minutes.

\section{Data analysis of Stage II}

Responses of each group were analyzed on the basis of three criteria discussed earlier, namely, originality of responses, variety and kinds of mathematics descriptors and approach in linking the ideas to the given task.

Responses from Group A were very short, less diverse and were limited up to elementary mathematical concepts. Most frequently used terms were limited to the names of different geometrical shapes, size and simple measurement units. Only two respondents moved beyond elementary concepts. For example, in describing a picture of circular ripples in water, all respondents except one, used only three mathematical descriptors: circles, concentrating circles, depth. None of them described the picture with a holistic approach. 
The only and most creative response was written in a paragraph using advanced mathematical descriptors such as concept of infinity, convergence, the idea of limit, increasing sequence of radii of concentric circles and others. In majority of other cases, mathematical descriptors used for describing the pictures were repetitive, concepts were of elementary level, no interconnection among concepts used for description and concepts were used fragmentally. Teachers did not use mathematical descriptors from advanced mathematical courses they were teaching.

Though participants of Group B were quick to list out characteristics of numeration system but they also struggled to move away from existing structure of numeration system. Majority of students changed the base from ten to other bases. All, except two, used bases less than ten. One of the participant used base twelve and other used base twenty. Almost all of them designed different symbols to represent numbers using shapes such as lines, stars, dots and other polygonal shapes. None of the participant could think of new rules to write numbers or writing numbers in other than horizontal order, or to think of numeration system without zero or without positional system.

Responses from Group C were very exciting. Grade VI students came up with interesting dialogues, story lines and other forms of writing using various adjectives, comparing numbers, describing their appearance and many more. Below are some excerpts from their responses:

Student I wrote a dialogue between 'Number 9' and 'Number 1':

Number 9: You are so linear, just a straight line.

Number 1: Yes, I am straight. It shows my confidence but you are so imbalanced..... looped on one side. Moreover, you can't stand without me. Only I can make you stand in the world.

Another girl student wrote a beautiful script detailing mathematical properties and features of each number from 0 to 9. She described 'two' as the most even number; 'one' as universal number; 'five' as historical number with links from early Greeks and 'zero' as the most powerful number. She used a social context to weave the string s of dialogues among numbers.

\section{Conclusions and Suggestions}

Though different tasks were developed for each group keeping in mind their level of mathematics education and their length of experience working and learning mathematics, the youngest group (Group C) was the most creative group among all the three. They could use interesting and sometimes funny analogies and adjectives. They could compare numerals on the basis of their physical appearance. They used numbers as measurement units and described numbers using their implicit properties such as even, square, multiples, factors and others. They wrote dialogue in imaginary contexts. The responses from Group $\mathrm{C}$ were more varied and courageous. University teachers were the most inflexible group. They could not even use those mathematical concepts which they were teaching at undergraduate level. There was hardly any newness in their responses. Descriptors were used loosely without describing them with reference to the picture. Responses from Group B demonstrated low level creativity. Participants could not extend their learning beyond existing line of rules. They could not explore new rules 
required to make numeration system. The only creative aspect of their responses was the mathematical designs used to write numerals.

The analysis of the study highlighted the conditioning of minds while learning, teaching and doing mathematics. It brings to our attention the more serious issues about how mathematics is presented and taught to our students. Once taught in a strict disciplined manner, it is preserved as a treasure and transferred with utmost care, year after year, decade after decade to the next generation of learners. Neither teacher brings any fun in mathematics learning or provides freedom of expression nor does mathematics curriculum provide any scope of creativity.

There are strong evidences establishing positive correlation between creativity and intelligence. (Rotigel \& Fello, 2005). Since creativity is directly related to intelligence and intelligence is developmental, small opportunities of creative tasks in mathematics learning can foster intelligence. If children are encouraged to think beyond the procedural regime of teaching mathematics then there is a strong possibility to avoid early signs of mathematics phobia among learners. Children shall be encouraged to think, talk and do mathematics from different perspectives since primary years to avoid rigidity in thinking. As it is evident from the findings, teachers who were associated with mathematics for so long, first as a student and later as teachers could find it hard to break the barriers. Similarly, university students were also uncomfortable in experimenting with already existing systems and rules. School children who were in their foundation years of understanding mathematics as a system were most flexible, imaginative and courageous to think out of box. It is therefore suggested that mathematics creativity shall be an integral part of school mathematics curriculum. Fostering mathematics creativity shall be one of the central aims of teaching mathematics since early years. Teachers shall be exposed to think creatively. Teachers shall be trained to develop creative ways to assess their students. Creativity is the most humanistic definition of mathematics. Mathematics is alive because it is creative. This perspective shall be the basis of designing any mathematics program.

\section{References}

[1] Rotigel,J.V. \& Fello, S. (2005). Mathematically gifted students: how can we meet their needs?. In S.K.Johnsen and J.Kendrick (Ed), Math education for gifted students ( pp 3-16). USA: Purfrock Press Inc.

[2] Runco, M. (2014). Creativity: Theories and Themes: Research Development, and Practice (2nd Edition). USA : Elsevier Inc.

[3] Simonton, K. (2014). Genius, creativity and leadership. In T.Rickards, M.K.Runco and S.Moger (Ed), The Routledge companion to creativity (pp 247-255). Oxon, UK: Routledge.

[4] Zhang and Sternberg. (2014). Intellectual styles and creativity. In T.Rickards, M.K.Runco and S.Moger (Ed), The Routledge companion to creativity (pp 256-266). Oxon, UK: Routledge.

*Corresponding author.

E-mail address: jyotisharmacic@gmail.com 